\title{
Review of updates on the prevalence and epidemiology of Acetaminophen poisoning in the United States and the United Kingdom
}

\author{
Article by Njoku Amara Chiemezie, L. \\ M.Sc Clinical Research, Texila American University, Nigeria \\ Email: deepwatersamara@gmail.com
}

\begin{abstract}
Paracetamol was licensed for assumedly safe worldwide usage in 1955 and is debatably the most common form of pain relief, headache palliative and hyperthermia medication used in both pediatric and adult populations in the Americas. Acetaminophen as it is commonly referred to in the United States is a component of very numerous treatment protocols for a wide range of ailments worldwide. Its patency permits has given rise to newer names in various countries using such names as paracetamol and panda. Although fatal and nonfatal liver based injuries, (some microscopic and others macroscopic) have been reported since 1966 due to overdose medications (usually self inflicted) due to self medications. Despite these problems, it's a reasonably safe drug when taken within its therapeutic dose range. Paracetamol poisoning is portrayed as a foremost causative factor in the emergence of acute liver damage in the Americas. It is note worthy that certain factors tend to favor the emergence of paracetamol induced liver damage like chronic use of alcohols, certain enzyme inducing drugs, and associated liver parenchymal diseases even under the circumstances of a normal therapeutic usage of the drug- paracetamol / acetaminophen. Certain questions beg for answers. Are there new findings from decades of pharmacovigilance? Is there a possibility of genetic mutations observed? Is paracetamol still steadfastly safe as portrayed in pregnancy as has been documented since 1966? These are some questions seeking updates.
\end{abstract}

Keywords: Hepatic failure; drug poisoning; pharmacovigilance; epidemiology; prevalence; hyper medication

\section{Introduction}

Acetaminophen is an analgesic and an antipyretic drug. It has ubiquitous applications and is readily available worldwide with no less greater potential for toxic effects as compared to other common pain relief medications like ibuprofen and aspirin ${ }^{[1][3 a]}$ but review of updates show it indeed has a much higher potential for events of hyper medication. According to Larson et al ${ }^{[2]}$ it is said to be the commonest direct etiologic agent in cases of acute hepatic failure in the United States and the United Kingdom. In England and Wales an estimate of over 40,000 cases of acetaminophen poisoning occurred from 1989 to 1990, (mortality of over $0.39 \%$ ) ${ }^{[3 b]}$. It is estimated that average of 175 deaths and 16 to 19 liver transplants occur as a result of poisoning each year in England and Wales.(See fig.1.) Acetaminophen overdose results in more visits to emergency units in the US than overdose of any other pharmacological substance, over 50,000 emergency room visits, 2,100 hospitalizations, and over 452 deaths due to acute liver failure per year. ${ }^{[4][5] .}$ A study of reported cases of acute liver failure in the USA noted that acetaminophen was the culprit in over $40 \%$ of all cases in adults, and over $23 \%$ of cases in under fives age groups. As at May 18, 2016, it is stated that acetaminophen poisoning has overtaken viral hepatitis as the leading cause of acute liver failure in the United States. (emedicine.medscape.com/article/820200-overview) 
Texila International Journal of Clinical Research

Volume 3, Issue 2, Dec 2016

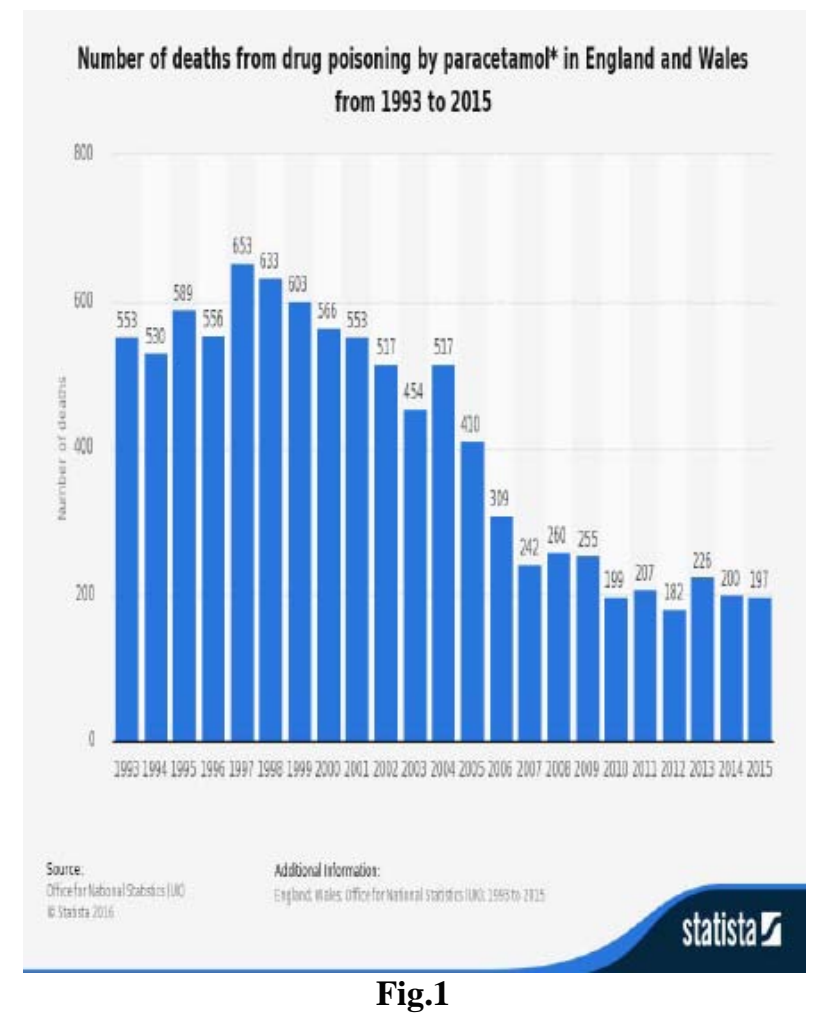

\section{Hyper dosages and suicide}

Paracetamol is one of the leading self prescribed drugs in cases of voluntary hyper medications. ${ }^{[5][6]}$ In the UK, paracetamol is the most common culprit in hyper dosage, responsible for more than $40 \%$ of oral intake of poisons admissions to the hospital and associated with an approximated over one hundred and fifty deaths per year.(http://bestpractice.bmj.com/bestpractice/monograph/337/resources/references). However, the incidence of poisoning in the US was above seventy thousand acetaminophen-related cases documented at the American Association of Poison Control Centers in 2006, with cases of young females out weighing all other gender or age based demarcations. There were approximately over 950 cases of severe paracetamol toxicity and over 97 cases of paracetamol-related deaths. (See fig.2\&3). The drug was also implicated as a drug of choice in voluntary self harm schemes amongst teenagers in the most developed economies of the world.

In a majority of developing countries, like Nigeria, the incidence of paracetamol poisoning rarely approximates that of the United States or United Kingdom rather it seems toxicities due to Tramadol and other narcotic agents hold sway amongst the teenage group 14 - 18years. Paracetamol overdose can result from paracetamol-only preparations but also from special combinations of paracetamol with other drugs like the popular combifen and cafégot brands in Nigeria. These paracetamol-containing preparations can be either prescription medication or nonprescription preparations. Over 49 million people are said to use paracetamol or paracetamolcombination products each 7day period in the USA.

There is documentation of the presentation of stages of clinical debility over hours in any case of acetaminophen poisoning. Within the first twenty four hours of ingestion, the victim will experience excessive sweating (diaphoresis), nausea and vomiting. There may be an ironical improvement of symptoms over the following forty eight hours but with the development of right upper quadrant pain. As from the $72^{\text {nd }}$ hour to the $96^{\text {th }}$ hour post ingestion without medical intervention, liver functions begin to fail and gastrointestinal problems may ensure. However, from $4^{\text {th }}$ day up to 2 weeks post ingestion, patient's liver problems may resolve in over $70 \%$ of all victims. The Rumack-Matthew normogram is a device for assessing probability of hepatotoxicity in acute overdose. (See fig.3.) 


\section{Self prescription}

Other important factors in the etiology of over dose of acetaminophen are homemadeprescribed regimen for all nature of pains, emergency department patients overuse of nonprescription pain killers, dental pain patients, the use of combination regimen duplicated in various products which may contain and provide increased quantities of acetaminophen unwittingly can lead to unintended overdose, and of course the vascular crisis of sickle cell anemia.

There are an increasing number of research reports of therapeutic paracetamol poisoning relating to the use of intravenous paracetamol in both the adult and pediatric age groups ${ }^{[7][8][9] .}$ Acetaminophen is available in both fast-release and long duration-release forms. The therapeutic dose is 10 to 15 milligram per kilogram per dose in children less than five years and 325 to 1000 milligram per dose in adults, given 4-6 times a day, with a maximum recommended daily dose of 80 milligram per kilogram in children or 4 gram in adults.

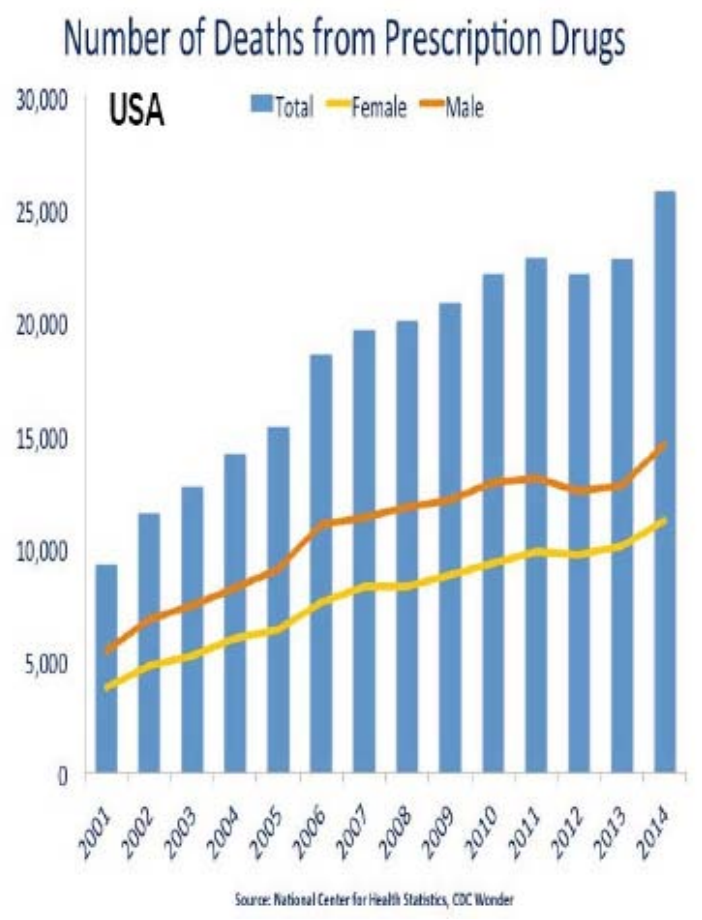

Fig.2. 
Texila International Journal of Clinical Research

Volume 3, Issue 2, Dec 2016

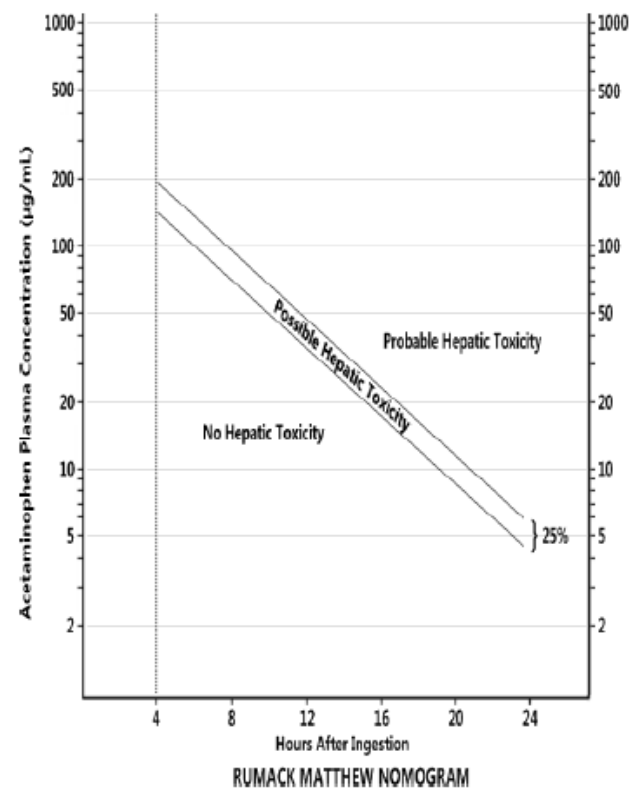

Fig.3*

*(Adapted from Rumack BH, Matthew H. Acetaminophen poisoning and toxicity. Pediatrics1975; 55(6):871-876.)

\section{Pharmacogenetics}

Baseline glutathione levels are an important consideration in determining pharmacogenetics which definitely varies per person. It is important to note that toxicity is less likely to result from a single dose of less than $150 \mathrm{mg} / \mathrm{kg}$ in a child or 7.5 to $10 \mathrm{~g}$ for an adult. However it is more likely to occur with single ingestions greater than $250 \mathrm{mg} / \mathrm{kg}$ or those greater than $12 \mathrm{~g}$ over a 24hour period. Noteworthy is the fact that $97 \%$ of all patients who ingest doses in excess of 350 milligram per kilogram develop severe liver toxicity unless appropriately treated. Acetaminophen exhibits $100 \%$ complete absorption from the intestines. Peak serum concentrations occur between $30^{\text {th }}$ minute and the $120^{\text {th }}$ minute post oral ingestion of therapeutic regime.

Factors causing delays in attainment of peak serum concentrations include co-ingestion of anticholinergic, co-use of morphine, codeines, tramadol and also the use of long duration release forms of the drug. Elimination half-lives range from 60minutes to 240 minutes for all paracetamol preparations, but elimination phase may be delayed in onset for extended-release preparations due to nature of its formulations. Longer half-lives greater than 240 minutes have been observed in patients with liver failure. The casualty rate from acetaminophen overdose worsens 48 hours after ingestion, reaches a peak on day 4 , and then eases off. The zenith indicator of worsening prognosis is the presence of acidemia. A mortality rate of over $92 \%$ without liver transplant was reported in patients whose $p H s$ was less than 7.30. Other indicators of poor prognosis are renal failure, liver encephalopathy, prothrombin time elevation, blood lactic acid elevation and low

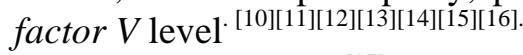

Suarez-Kurtz et al ${ }^{[17]}$ published an article in 2014 proving that ethnicity played a major role in determining adverse effects to acetaminophen. Ward et al., $2001^{[18]}$ carried out a research linking degree of adverse reactions or toxicities to certain nutritional deficiencies.

\section{Pharmacovigilance}

By August 2013, the United States FDA had issued a warning on the reporting of a skin dyscrasia directly linked to the drug acetaminophen as discovered by ongoing pharmacovigilance protocols. This was a side effect originally confined to allergies to non steroidal antiinflammatory agents. FDA issues a safety alert to the public on $1^{\text {st }}$ august 2013 . By $14^{\text {th }}$ January, 2014, FDA directed all doctors and pharmacists to desist from prescribing acetaminophen or any combined therapy of more than three hundred and twenty five milligrams of the drug. Major 
manufacturers of acetaminophen products with dosages more than 325mg acetaminophen have stopped marketing same in the United States by $28^{\text {th }}$ of March, 2014. Latest reviews as at $1^{\text {st }}$ September 2015 has questioned the safety on continued use of acetaminophen as a routine pain medication during pregnancy. Source ( $w w w . f d a . g o v)$.

\section{Legislative interventions.}

Keith Hawton et al ${ }^{[19]}$ published (2013) in the British medical journal assessing the long term effect of a legislation by the UK parliament seeking a reduction in size of paracetamol packs as an intervention to curb the rising incidence of paracetamol poisoning. The law was passed in September 1998. The research stated that there was $43 \%$ reduction in deaths associated with acetaminophen poisoning in over 11years post introduction of the legislation in the United Kingdom. (See fig.3).
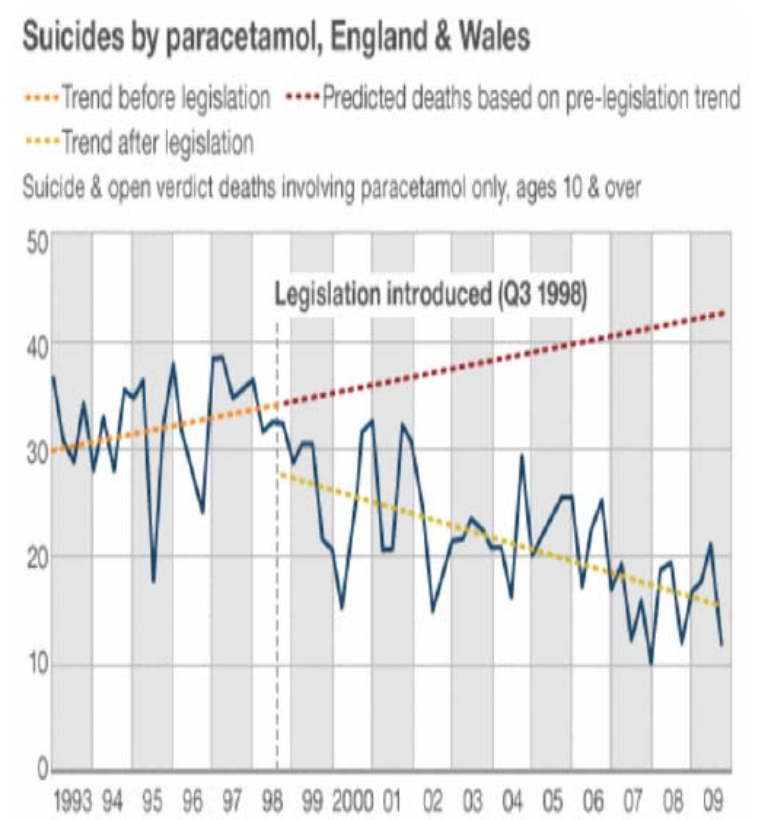

Source: BMJ

Fig.4

\section{Methods}

The research method was a Meta-analysis type, collating and analyzing data from online scientific data bases, abstract guides and references, content analysis, published articles, medical textbooks and research materials from Universities.

\section{Results and conclusions}

The issue of acetaminophen poisoning is an ever present challenge in our world. As long as acetaminophen remains an over the counter medication around the world, the prevalence rates of its toxicity will remain alarmingly high. The pharmacovigilance protocols in the United States had received updates in emergence of new adverse effects of the drug and had issued an alert to its healthcare professionals. The United Kingdom issued a legislation which seemed to have a tremendous positive effect on the prevalence of the drug poisoning over a period of 11 years. The continual surveillance of Acetaminophen in the United States and the United Kingdom is commendable and should be emulated by the under developed countries as a standard practice. The research regarding safety of paracetamol in pregnancy is still ongoing although FDA of the United States had issued a query on September, 2015 regarding the matter. 
Texila International Journal of Clinical Research

Volume 3, Issue 2, Dec 2016

\section{References}

[1]. Efficacy and safety of acetaminophen vs. ibuprofen for treating - NCBI

[2]. www.ncbi.nlm.nih.gov/pubmed/15184213 by DA Perrott et al- 2004 -.

[3]. Larson AM, Polson J, Fontana RJ, Davern TJ, Lalani E, Hynan LS, Reisch JS, Schiødt FV, Ostapowicz G, Shakil AO, Lee WM; Acute Liver Failure Study Group. (December 2005). Acetaminopheninduced acute liver failure: results of a United States multicenter, prospective study. Hepatology (Baltimore, Md.) 42 (6): 1364-72.

[4]. Sheen C, Dillon J, Bateman D, Simpson K, Macdonald T (2002). "Paracetamol toxicity: epidemiology, prevention and costs to the health-care system". QJM: monthly journal of the Association of Physicians 95 (9): 609-19. doi:10.1093/qjmed/95.9.609. PMID 12205339. 3b. Buckley N, Eddleston M (December 2005). "Paracetamol (acetaminophen) poisoning". Clinical evidence (14): 1738-44. PMID $16620471 \ldots$

[5]. Gunnell D, Murray V, Hawton K (2000). "Use of paracetamol (acetaminophen) for suicide and nonfatal poisoning: worldwide patterns of use and misuse". Suicide \& life-threatening behavior 30 (4): 313-26. PMID 11210057.

[6]. Hawkins LC, Edwards JN, Dargan PI (2007). "Impact of restricting paracetamol pack sizes on paracetamol poisoning in the United Kingdom: a review of the literature". Drug safety: an international journal of medical toxicology and drug experience 30 (6): 465-79.doi:10.2165/00002018-20073006000002. PMID 17536874.

[7]. Khashab M, Tector AJ, Kwo PY (March 2007). "Epidemiology of acute liver failure". Current gastroenterology reports 9 (1): 66-73. doi:10.1007/s11894-008-0023-x. PMID 17335680.

[8]. Lee WM (July 2004). "Acetaminophen and the U.S. Acute Liver Failure Study Group: lowering the risks of hepatic failure". Hepatology 40 (1): 6-9. doi:10.1002/hep.20293. PMID 15239078.

[9]. Davidson DG, Eastham WN. Acute liver necrosis following overdose of paracetamol. Br Med J 1966; 2:497.

[10]. Seeff LB, Cuccherini BA, Zimmerman HJ, et al. Acetaminophen hepatotoxicity in alcoholics. A therapeutic misadventure. Ann Intern Med 1986; 104:399.

[11]. Zimmerman HJ, Maddrey WC. Acetaminophen (paracetamol) hepatotoxicity with regular intake of alcohol: analysis of instances of therapeutic misadventure. Hepatology 1995; 22:767.

[12]. Maddrey WC. Hepatic effects of acetaminophen. Enhanced toxicity in alcoholics. J Clin Gastroenterol 1987; 9:180.

[13]. Whitcomb DC, Block GD. Association of acetaminophen hepatotoxicity with fasting and ethanol use. JAMA 1994; 272:1845.

[14]. Schiødt FV, Rochling FA, Casey DL, Lee WM. Acetaminophen toxicity in an urban county hospital. N Engl J Med 1997; 337:1112.

[15]. Benson GD. Hepatotoxicity following the therapeutic use of antipyretic analgesics. Am J Med 1983; 75:85.

[16]. Watson WA, Litovitz TL, Klein-Schwartz W, et al. 2003 annual report of the American Association of Poison Control Centers Toxic Exposure Surveillance System. Am J Emerg Med 2004; 22:335.

[17]. Lee WM. Acetaminophen and the U.S. Acute Liver Failure Study Group: lowering the risks of hepatic failure. Hepatology 2004; 40:6.

[18]. Pharmacogenomic implications of population admixture: Brazil as a model case.

[19]. Suarez-Kurtz G, Paula DP, Struchiner CJ

[20]. Pharmacogenomics. 2014 Feb; 15(2):209-19.

[21]. Ward R. M., Bates B. A., Benitz W. E., Burchfield D. J., Ring J. C., Walls R. P., et al. (2001). Acetaminophen toxicity in children. Pediatrics 108 1020-1024 10.1542/peds.108.4.1020 [Cross Ref]

[22]. Long term effect of reduced pack sizes of paracetamol on poisoning deaths and liver transplant activity in England and Wales: interrupted time series analyses. BMJ 2013; 346 doi: http://dx.doi.org/10.1136/bmj.f403 (Published 07 February 2013) Cite this as: BMJ 2013;346:f403,Keith Hawton, professor of psychiatry and director centre for suicide research1, Helen Bergen, researcher1, Sue Simkin, researcher1, Sue Dodd, scientific assessor2, Phil Pocock, principal statistician3, William Bernal, reader in hepatology4, David Gunnell, professor of epidemiology5, Navneet Kapur, professor of psychiatry and population health6 
[23]. University of Oxford Centre for Suicide Research, Department of Psychiatry, Warneford Hospital, Headington, Oxford OX3 7JX, UK

[24]. Post Authorisation Signal Unit, Vigilance and Risk Management of Medicines, Medicines and Healthcare products Regulatory Agency, London, UK

[25]. Statistics and Clinical Audit, NHS Blood and Transplant, Stoke Gifford, Bristol, UK

[26]. Liver Intensive Therapy Unit, Institute of Liver Studies, King’s College Hospital, London, UK

[27]. University of Bristol, School of Social and Community Medicine, Canynge Hall, Bristol UK

[28]. University of Manchester, Centre for Suicide Prevention, University Place, Manchester, UK 